\title{
REGARDING THE TRANSFERABILITY OF SKILLS AND COMPETENCY AND THEIR DEVELOPMENT IN THE COURSE OF EDUCATION IN MATHEMATICS IN PRIMARY SCHOOL
}

\author{
Peter Petrov, ${ }^{1}$ Maria Temnikova ${ }^{2}$
}

\begin{abstract}
:
Introduction: The building up of transversal competencies and the creation of transferable skills is one of the most important factors for efficient education of mathematics in primary school.

Purpose of study: The purpose of this article is the development of the concepts of transferable skills and transversal competencies, as well as the alternatives for their creation and development in and through the education of mathematics in Grades $1-4$.

Methods: For the purposes of this study, longitudinal qualitative and quantitative research was applied. The following methods were used: experiment, observation, test, analysis of the content, and mathematical-statistical methodology for data processing.

Findings and results: The percentage of the Grade 4 students who wrongly correlate the text of the mathematical task to a given mathematical model decreased from $42,31 \%$ to $3,85 \%$. Also, the percentage of the students who were not able to create a mathematical model decreased from $38,46 \%$ to $7,69 \%$. The percentage of the students who correctly created mathematical models increased from $26 \%-38 \%$.

Conclusions: Transferable skills and cognitive transversal competency for processing of information were developed completely.
\end{abstract}

UDC Classification: 373; DOI: http://dx.doi.org/10.12955/cbup.v5.1035

Keywords: strategies, skills, competences, competencies

\section{Introduction}

The transition to a post-industrial and informational society in world scale is characterized with the globalization of the economy and the financial resources, as well as with high mobility of the work force which requires new types of competencies and skills in personal, social and professional aspects. It can be said that the world trends related to the content and the organization of education are: orientation to understanding and rationalization of the knowledge; restriction of the role of the reproductive knowledge; and stimulation of students' creativity.

\section{Purpose, object, subject and aim of the study}

The purpose of the study is to systematize and develop a basic theoretical formulation of transversal skills and transversal competencies. Following this, to create a system and series of mathematical tasks, and to study the level of transversal competencies forming in and through education of mathematics in Grade 4.

The object of the study is the process of education of mathematics in Grades $1-4$.

The subject of the study is the combination between productive and reproductive strategies, and the related approaches and methodologies of work for development of cognitive transversal competency for the processing of information and the development of transferable skills in the education of mathematics in Grades $1-4$.

To achieve this goal the following tasks needed to be completed:

1. The theoretical analysis of works of Bulgarian and foreign authors related to the competency approach, competencies, competencies, transversal competencies and transferable skills.

2. To apply problem-productive strategies for the development of technological and methodological systems of work in the education of mathematics.

3. To study the efficiency of the applied problem-productive strategies as part of the methodological system of work in the educational process of mathematics in Grade 4.

\footnotetext{
${ }^{1}$ Trakia University - Stara Zagora, Pedagogy Faculty, pdp@dir.bg,

${ }^{2}$ Trakia University - Stara Zagora, Pedagogy Faculty, mpt66@abv.bg
} 
The following criteria were proposed: the knowledge and skills to choose a mathematical model and to work with it; the knowledge and skills to create a mathematical model; the knowledge and skills to bring into proper correlation to the initial one newly received information.

In psychology, pedagogy, and the particular methodologies there is no common understanding in the differentiation between the nature of skills and habits in general. There is a widespread view that the skills represent "knowledge in action" and the habit is an action whose components have become automatic as a result of their multiple repetitions (Andreev, 1987, p.90). On the other hand, the founder of cognitive psychology, Ulrich Naiser, suggested that the cognitive activity of a person is better explained and associated with the process of acquiring of skills. (Naiser, 1976).

Another concept with a strong explanatory function offers the view that "during scrutinizing the process of acquiring the skill to perform certain activity in its entirety, the structure of this skill (this could be painting a picture, singing, drawing, solving mathematical tasks, etc....) often appears to be multicomponent. This will include not only the perception, understanding, and coordination but also the theoretical and the methodological knowledge, creative thinking, and different habits (perceptive, intellectual, and life driving". (Ylin, 1986, p.139). In this case the issue with the automation of skills is not addressed because the skill as an entire process cannot be automated and habits represent part of the skills.

There are two aspects of understanding of the concept of "skill" - the aspect of action and the aspect of operation. The first one is related to the ability to do whatever action, and the second one the ability to perform certain activities and operations.

Studying the skills to solve mathematical tasks in the aspect of action supposes that the main substance in this skill is the quality and the efficiency of execution of the task. In the same time, automation of this skill is not necessarily an indication for the possession of this ability. These aspects suggest a complicated hierarchy structure involved in the skill to solve mathematical tasks.

Brunner pointed out something very important and namely the fact that "the process of forming of habits and the process of solving of mathematical tasks are very similar in the early age of little children" (Brunner, 1977, p. 272). According to us, this means that the two processes facilitate each other.

The relationship between the skill and the ability to solve mathematical tasks is displayed in the activity "task resolving" where these two features represent the two sides of its effective application. The difference is that the skill to solve mathematical tasks is related mainly to congenital (inborn) qualities. This would assure constant success in one or more activities and can explain the differences in the ease and swiftness in acquiring the necessary knowledge and skills for solving mathematical tasks.

Boris Minchev developed an interesting concept affirming that the transversal function of skills is low due to their locatedness. He based his conclusions on the context nature of the skills, especially the ones that have in their structure multiple components of acceptance and action. This concept in certain respect can be supported by the following fact. Through big scale studies performed during the second half of 20-th century it was found that the memory and perception of high level chess players do not differ from the ones of the ordinary people when they are not in a process of chess playing. "Actually, the general intellect is transversal, i.e. the capability to form skill, but not the structure of the skill itself." (Minchev, 1991, p.80).

The relationships are oriented to the system of values in life and shall be analyzed as a complex of assessment reasoning and emotional charge directed to the environment - to the nature, to society as a whole, to human relations. Typically, once formed, these relations are very stable.

For the first time in 1996, Bernard Ray (Ray, 1996, p.169) brought up the issue of transversal competencies. He noted that through "his transversal competency a man gives sense to the situation... As a result, transversality can be described as the simultaneousness which exists between multiple situations united by their common sense assigned to them by the subject..." Yana Merdzanova wrote about the existence of two aspects of transversal competency: as function and as intention. "In reality, the competency-function cannot go beyond the specifics but the competency-intention as a point of view, as an approach, as a manner, as a style - it can and it must be pedagogically formed and to be transferred through different ages and activities. This is the sense that every person assigns to the specific situation in which he acts through his narrow competencies". (Merdzanova, 2005, p. 62) 
It is well-known about the existence of four main groups of transversal competencies defined by Bernard Ray: „autonomy and responsibility, communication competency, organizational and methodological competency, and cognitive competency for processing of information." (Merdzanova, p.165). Transversal competencies as such are universally valid. It seems that during the process of studying the ability and the skills to solve mathematical tasks as integral parts of the transversal competencies, the accent shall be put on their semblance of competency as a style and approach for solving mathematical tasks. The process of "transversing" presumes an active mind and before all, generalization. The last requires the actualizing of existing knowledge, abilities, habits, relations in respect of orientation in a new mathematical task (analysis, abstract thinking), the creation of conditions for qualification (assessment) of certain objects, and the connection of the new mathematical task to antilog ones, as well as summary and generalization. All this represents the foundation of the „actual transversal process.“ (Karagyozov, 1984, pp.77-83). The transversion of experience depends on personal subjective qualities like the ability to do wide classification ns, and the ability to participate in "associative games" and flexible thinking. This description demonstrates that the realization of an efficient transversal process would require solving of mathematical tasks representing complicated, repeatable situations.

Transversion is an important psychological pre-requisite for fast and easy acquiring of new knowledge, habits, and skills. It is simultaneously a condition for learning and a result from learning, "a bridge between present experience and newly acquired ones." (Tsanev, 1968, pp.187-235). The physiological basis of the transversion is the mechanism for relocation or switching over of the relative connection due to mutual influence (not always realized) and the interconnection of one system of temporary nerve connections with another.

It is worth mentioning three circumstances that the possibility for transversion can be explained with: the unity of the brain activity in entirety; the integrity of the person where each particular acquisition of ability and skills has got an effect on the entire system; similar and/or identical elements in different kinds of labour and study; the flexibility of the mind, of the application of the habits, of the dynamic stereotype and its transversing from one area to another. (Dessev, 1996, p.461).

A process for systematic accumulation of educational competences in mathematics is realized in each one of the Grades (from Grade 1 to Grade 4) of the primary school. These educational competencies represent a system of interacting specific mathematical competencies and key competencies. The teachers are of significant importance in this long and complicated process. They are the professionals who shall direct their efforts towards the creation of universal competencies, transversal competencies and transferable skills which will help to avoid the fragmenting of knowledge, in order to create specific competencies not only in respect of that particular subject but also in respect of all other subjects which are being studied.

This work studies the cognitive transversal competency for the processing of information and transferable skill as an object of creative diagnostics.

An education in mathematics in Grades $1-4$ aiming at creating a competency can be with good quality if this education is cast and developed through the introduction of tactical and strategical studying. This is the reason why these two types of studying are used to achieve the final goal.

During the process of studying existing works related to productivity, productive thinking, and productive activities of the students it was found that there are multiple publications about the subject, for example: Vigotskiy. In all the studies, one can clearly identify the connection between the productivity and the aims, the achieved results from the education on one side and the process of achieving these results on the other. In the United States and European countries specialists apply effective productive didactical strategies and approaches towards education. Priority is given to the active studying "through discovering" during the process of the activity.

Two approaches for teaching mathematics in the primary school can be conditionally distinguished. The first approach reflects the traditional education and is of a re-productive nature, offers knowledge prepared in advance which the student must learn and reproduce. The second approach aims at overcoming the re-productivity in the process of education. It activates the mental activity, creativity, active participation, and independence of the students. Jiordan relates this to "studying through discovering" (Jiordan 1995, pp. 114-115) and to "following the spontaneous needs and interests of the 
students." On the basis of these two approaches it is possible to build up two types of strategies: reproductive and productive. A problem-productive strategy: complex technology together with its related methodology of work was built up over the research process. During the application of the problem-productive strategies in the process of solving mathematical tasks, the competency approach was used and the following productive and reproductive methods were combined: variable exercises, creative type exercises, heuristic discussions, comparison, inductive and deductive methods, analytic and analytic-synthetic methods, reproductive discussion, exercises after given sample, demonstration, and observation, etc. During its application in the educational process and based on the options offered by D. Coats and J. Voz (Vitanov, 1999) priority was given to one of the following activities: activities of the students subjected to the study and related to observation and communication during applying of the strategy, practical activities of the students subjected to the study; mathematical research done by the students; and illustrative practical activity of the students during applying of the strategy.

For the purposes of the application of the methodology system of work, a problem-productive strategies series of mathematical tasks were created. Each one of them was related to a separate chapter of the educational content in mathematics and was aimed at acquiring knowledge, the creation of transferable skills, and the building up of cognitive transversal competency for the processing of information. For the creation of the series of mathematical tasks our main standing points were: they are the main tool for the formation of transversal competency, mathematical tasks from different areas were included for the purposes of forming separate parts of the transversal competency; they are mutually complimentary and create complex repeating situation.

\section{Results}

During the period 2004 - 2012, research regarding the creation of transversal competencies in the education in mathematics in Grades 1 - 4 was performed (Temnikova, M., Own scholarly essay, 2016). 112 students were subjected to the study. The results regarding transferable skills and cognitive transversal competency to process information are presented in this article.

From one side, the set of tools for diagnostics was created after analysing international projects TIMSS, and PIRLS и PISA as they are leading examples in the area of testing the success of students From the other side, the state legislation of Republic of Bulgaria and the requirements regarding the education in mathematics in Grades $1-4$ were also subjected to deep analysis for the purpose. Analysis of the results of the tests from the entry and from the exit diagnostics as well as a comparative analysis of these results was performed. The data from the comparative analysis of the entry and the exit diagnostics related to the knowledge and the skill to select a mathematical model, to create a mathematical model, and to correctly correlate newly received information to initial information, are presented in the below diagrams.

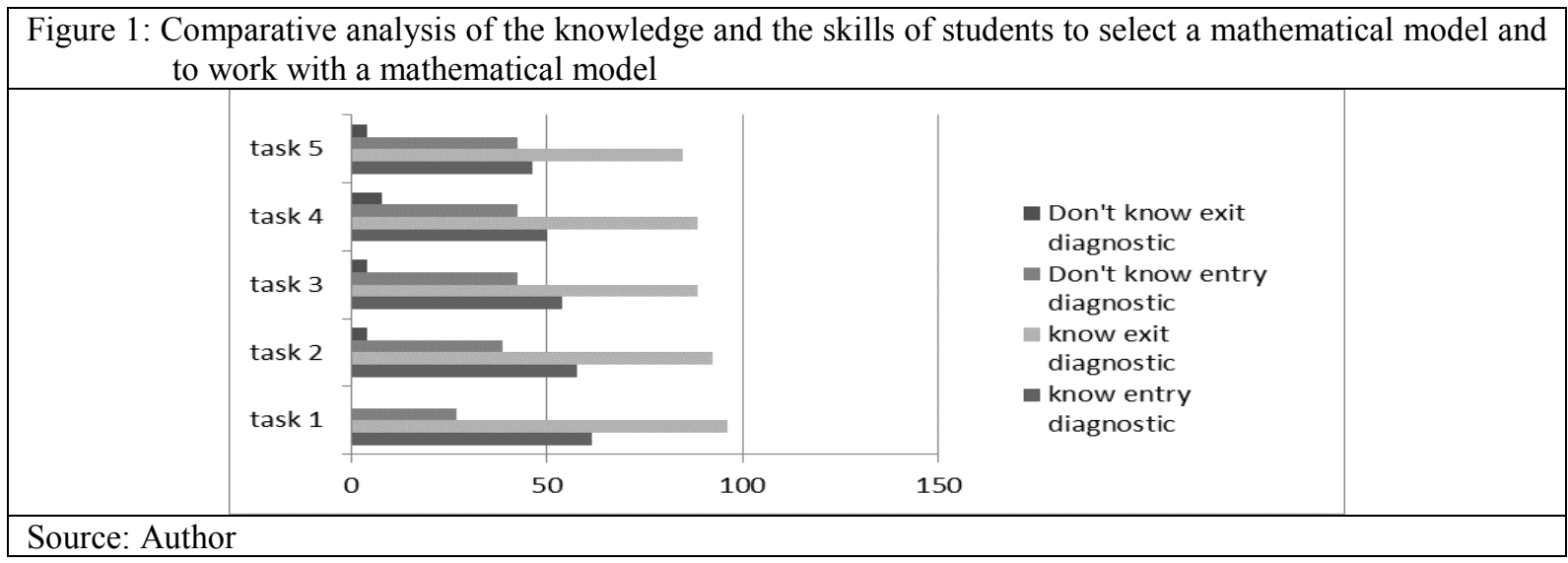

The received data demonstrate the presence of a statistically significant difference between the results received from the entry and from the exit diagnostics of the relative portions of students subjected to the study in respect of knowledge, skills, and transversal competencies. After applying the methodology system of strategies, methods, and procedures the percentage of the Grade 4 students who worked correctly was increased with $34 \%-38 \%$ on average. The percentage of the students who 
didn't know and failed to correlate the text of the mathematical tasks to a given mathematical model decreased from $42,31 \%$ to $3,85 \%$. The percentage of the students who correctly created the mathematical model increased from $26 \%$ to $38 \%$. The percentage of the children who did not know and failed to create a correct mathematical model decreased from $38,46 \%$ to $7,69 \%$. The level of knowledge, skills and specific mathematical competencies of the Grade 4 students to create and work with a mathematical model increased. The percentage of the children who worked correctly and fully completed the mathematical tasks increased from $38 \%$ to $46 \%$. The percentage of the students who worked incorrectly and failed to fully complete the mathematical tasks decreased from $38,46 \%$ to $3,85 \%$. There were no students who failed to solve five of the tasks included in the exit level test.

\begin{tabular}{|l||c|c|c|c|}
\hline Figure 2: Comparative analysis of the knowledge and the skills of the students to create a mathematical model \\
\hline
\end{tabular}

Figure 3: Comparative analysis of the knowledge and the skills of the students to correlate correctly new information to the initial information.

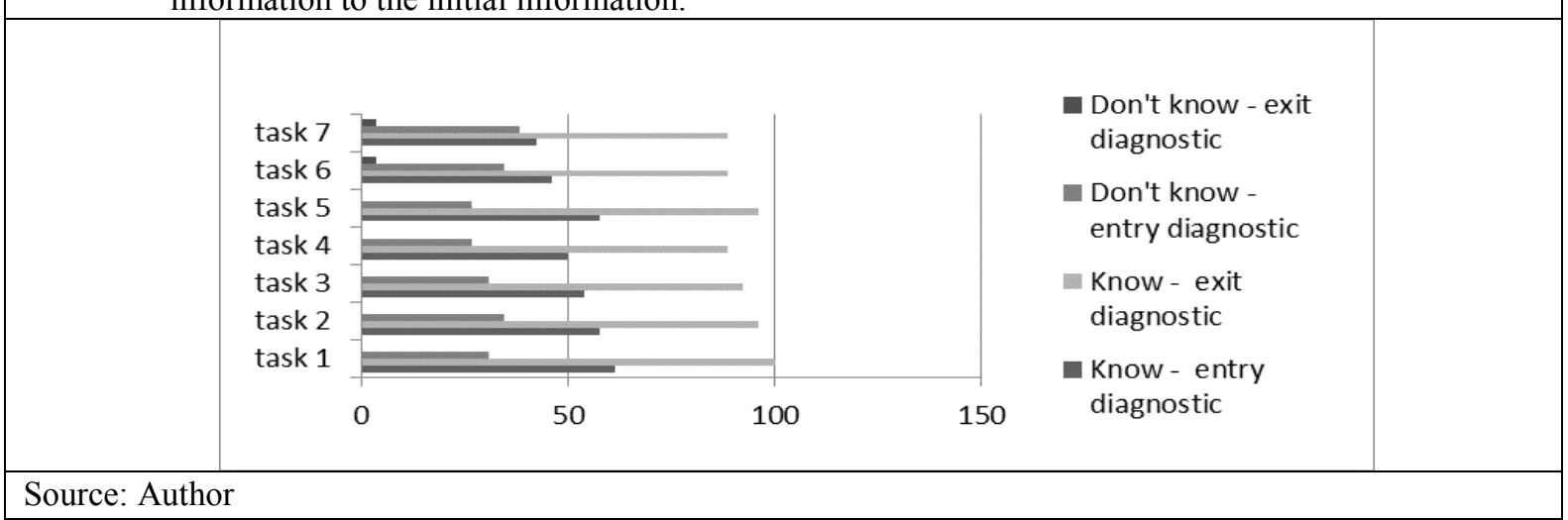

\section{Conclusion}

Based on the results of the research, the following conclusions can be made: transferable skills and the transversal competency to process information are getting developed completely. The Grade 4 students learn to study a group or groups of data, apply different techniques for processing and selection of information, can analyse, compare and synthesize, can decode information, can transfer from one semantic system to another and from the language of the text of the task to the language of mathematics, and can induce and deduce.

The development of the transversality as a characteristic of the skill is not proportional to its efficiency. High transversality of a particular skill could occur in the stage of "advanced beginner" and later be lost in the stage of "expert," but the efficiency could be greater. In this case it is not appropriate to separate a group of transversal skills as the basis for their classification as it does not have permanent structure. High transversality doesn't necessarily mean high efficiency. The fact that a particular skill has got higher level of transversality will not authorize the attribution of characteristics like universality and efficiency to it.

It will be more appropriate to talk about transversal competencies (which include skills as well) than about transversal skills. The transversal competencies do not automatically lead to the development of efficiency in a particular activity. 
Instead of talking about transversal skills, it will be more appropriate to talk about skill to transverse. Thus we preserve in greater extend the authenticity of the phenomenon that we study.

The form of the mathematical task for the development of a skill to transfer shall impose a complicated situation in closer areas. There are similarities between the approach of imposing a constructive mathematical task and the approach of involving the development of descriptions of the act of solving the mathematical task. Also, there are similarities in the most important specifics of the mathematical tasks like variability, anticipation of several alternatives of the task solution, analysis at the end of the mathematical task, and the offering of several similar approaches for the task's solution, as well as searching of similarities in the process of their application (open transversality).

\section{References}

Andreev, M. (1987). Didactics. Sofia, People Education Publisher.

Borisova, T. (2017). Foundations of reading literacy Grade 1-4. Stara Zagora

Bruner, D. (1977). Psychology of Knowledge. Moscow.

Dessev, L. (1996). Pedagogical Psychology. Sofia, Aksony Publisher.

Jordan, A. (1995, March). Do the new educational models represent rejection of the constructivism? Prospects. UNESCO, issue No. 93, Volume XXV, No.1.

Karagiozov, I.. (1984). Regarding transfer of skills and knowledge. Issue No.2.

Merdzanova, Y. (2005). Multisensory principle in education and in life. Sofia.

Minchev, B. (1991). Situations and skills. Sofia, University Publisher "Kl. Ohridski”.

Naiser, V. (1976). Cognition and Reality. San Francisko.

Rey, B. (1996). Les competences transversals en question. Paris, ESF.

Temnikova, M. (2016). Building-up of transversal competencies in the education in mathematics in Grades 1-4. Stara Zagora, Own scholarly essay.

Tsanev, Ts. P. (1968). To the psychology of transfer of knowledge. Annual edition of Sofia University, Faculty of Philosophy-History, Book II - Pedagogy, Sofia.

Vitanov, L. (1999). Productive strategies for education in technics and technologies in the primary school classes. Sofia, Veda-Slovena Zh.G Publisher.

Ylin, E.P.(1986). Skills and habits-unsolved issues. Psychology issues. Issue No.2. 